\title{
Comparative performance analysis of bridgeless boost and bridgeless buck converter for UPS application
}

Khairul Safuan Muhammad, Rahimi Baharom, Siti Zaliha M.N, Wan Noraishah Wan Abdul Munim

Faculty of Electrical Engineering, Universiti Teknologi MARA, Malaysia

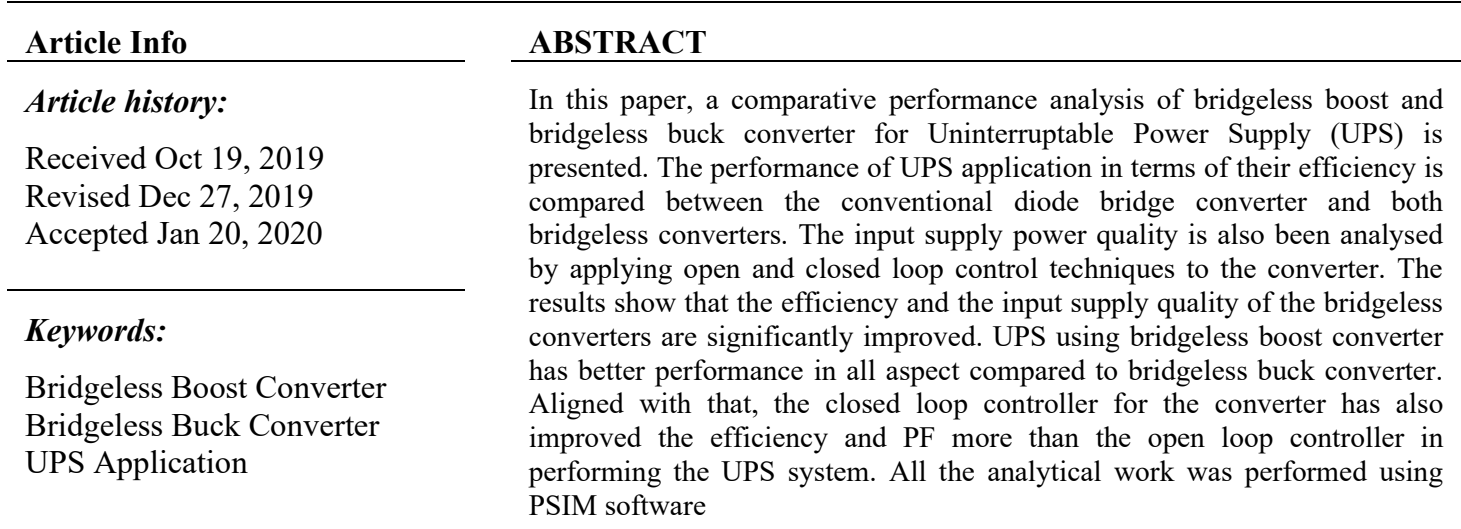

This is an open access article under the CC BY-SA license.

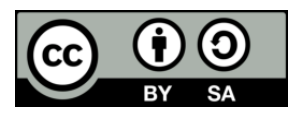

Corresponding Author:

Khairul Safuan Muhammad,

Faculty of Electrical Engineering,

Universiti Teknologi MARA, 40450, Shah Alam, Selangor, Malaysia

Email:ksbm77@gmail.com

\section{INTRODUCTION}

An uninterruptible power supply is a gadget that can supply the interruptible supply to the load and generally known as UPS. UPS framework has been introduced broadly in the network centre, communication system, financial institution and medical equipment in providing a reliable and continuous power. Accordingly, arrange framework stoppages have a major effect to the public and UPS has been expanded the significance in giving stable power supply [1-3].

As though the power disappointments of power outages occur, computer devices like workstations and servers break down may happen and can prompt different issues like program malfunction and loss of important data. Besides, even a momentary voltage drop in the factory production lines can experience in system stoppages, defective products and the worst-case scenario, it can damage the equipment. Consequently, to stay away from these issues, UPS can be introduced in computers, network systems and production lines which conceivable to operate systems with stability and efficiency by the various functions of UPS [4].

With deterioration of worldwide condition and energy crisis, reducing the pollution and enhancing the energy conversion efficiency had pulled wide consideration in the entire world. Maintaining a high efficiency across the entire line range raises a major challenge for AC to DC rectifiers [5-10].

For different applications like UPS, the AC input voltage frequency is 50 hertz produced by the electrical supply that converted to a DC supply. Rectifier Bridge is typically used to demonstrate the conversion of AC to DC. The loss of bridge rectifier involves in power stage loss by enhancing the power 
level [11-16]. At any operating condition, bridgeless can be defined when the circuit consist of rectifier bridge and there are only two semiconductor devices through the current path [17-21] .

Uninterruptible Power Supplies (UPS) system is used when the input power source or mains power fails. UPS is a non-stop power framework, an electrical device that gives emergency power to a load. A UPS different from an emergency power system or standby generator that will give close prompt assurance from input power interruptions by supplying energy stored from batteries. The on-battery runtime of most uninterruptible power sources is moderately short yet adequate for a standby power source or appropriately close down the protected equipment.

The circuit diagram shown in Figure 1 is a simple form of the commercial UPS that can deliver 48 VDC. In the power failure condition, the battery will take over. The transformer steps down the main voltage to $12 \mathrm{VAC}$ and then the bridge rectifies it. The rectified signal is then smooth by the capacitor. During normal operation, the battery will be charged by means of diode D1 and the regulator gets supply from diode at D3. At the output of the load terminals 48 VDC is applicable. During power failure, the main supply is cutoff and the battery will take over to supply current to the 48 VDC output terminal through diode at D2. The function of diode at D1 is to make sure there is only one-way flow of current during battery mode. However, the diode bridge suffer from high conduction losses thus reduces the overall efficiency of the converter.

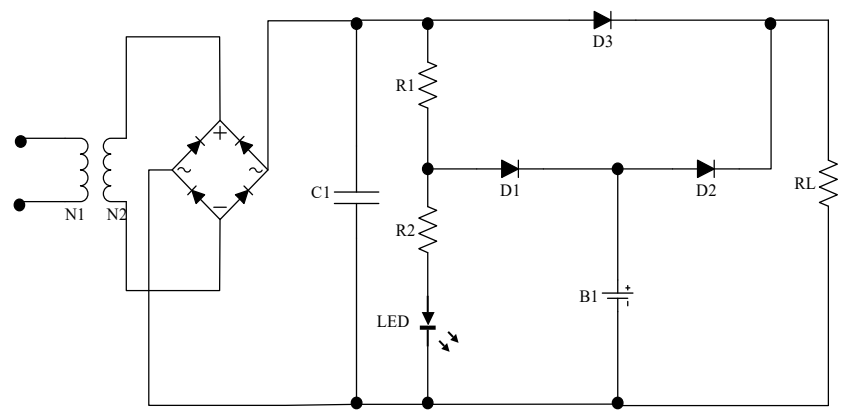

Figure 1. Basic UPS system circuit

Meanwhile, the increasing of high efficiency requirements has been giving the chances to look for any potential opportunities to reduce the converter losses [22-23]. The most common solution is by using conventional rectifier which widely used for various kinds of servers, workstations and computers. However, it leads to high conduction losses since the input current always flow through the two bridge diodes and a power switching device. The conduction losses from diodes presents in front end rectifier has decrease the overall converter efficiency, mainly at the input voltage and high output power. Therefore, bridgeless topology is introduced to increase the converter performance [24-26].

The proposed converter consists of two types of bridgeless topology that will be studied which are boost and buck converter for UPS application. These two will be analysed and simulated by using PSIM simulator by using two methods of controller. All the analysed data will be recorded by varying the parameters and duty cycle in order to get the desired load output. In order to get the output load of 48 VDC, the input voltage of boost circuit would be $12 \mathrm{VAC}$ whereas the input voltage for buck circuit would be in the range of 90-230 VAC. The conventional rectifier of diode bridge will be compared with the topologies proposed in terms of their efficiency. To get the highest possible efficiency in UPS performance, power factor (PF) is highlighted by using the PF correction (PFC) in the controller circuit.

The objectives for this study is to develop a new UPS application using bridgeless converter topology and to analyse the performance of the proposed UPS topology. The proposed topologies are explained in the next section followed by the simulation and results presented.

\section{BRIDGELESS CONVERTER}

Figure 2 shows the circuit of bridgeless boost rectifier. The inductor is split and were placed on the $\mathrm{AC}$ side in performing the structure of boost converter unlike the conventional converter circuit. It can be said that the difference between bridgeless and conventional converter circuit is that the inductor current of bridgeless will only flow through two semiconductor devices which will lead to reduce the conduction losses.

Int J Pow Elec \& Dri Syst, Vol. 11, No. 2, June 2020 : $801-809$ 
This topology also had replaced the slow diodes of conventional topology by using MOSFET body diode regulated by pulse-width-modulation (PWM. Thus, the efficiency of the bridgeless topology is improved due to less conduction losses occur. Besides, the bridgeless topology not only reduce the conduction losses, it also reduces the total components in the circuit compared to conventional circuit.

Based on the Figure 1, for positive half cycle, as MOSFET S1 turns on, the inductor L1 stores energy and current flows through the path of inductor L1, MOSFET S1, the internal diode of MOSFET S2 and inductor L2. When the MOSFET S1 is turns off, L1 will then discharges the stored energy by D1 to the load. Hence, the current flows through the path of diode D1, load R1, internal diode of MOSFET S2, inductor L2 and input line. For the negative half cycle, as MOSFET S2 turns on then, the inductor L2 will stores energy and current flows through path of inductor L2, MOSFET S2, internal diode of MOSFET S1 and inductor L1. When the MOSFET S2 is turns off, L2 discharges stored energy by D2 to load and current flows through the path of diode D2, load R1, internal diode of MOSFET S1, inductor L1 and input line. The MOSFET S1 can only be driven either on and off in positive half cycle whereas MOSFET S2 driven only in negative half cycle. Both MOSFETs driven on/off simultaneously as the freewheeling diodes in S1 and S2 providing right current flow in every altenation of the input line.

The bridgeless buck converter shown in Figure 3, utilize two consecutive associated buck converters, which operate in alternative halves of the line-voltage cycle. It consists of a unidirectional switch carried out by diode that series with switch, freewheeling diode, filter inductor, and output capacitor. During the conduction of a switch, the input current will always flow through only one diode. The input bridge diodes in which two diodes carry the input current is neglect to improve the efficiency [13].

During the positive half cycle, the operation consists of unidirectional switch of diode D1 series with switch S1. As S1 in turns on, the filter inductor L1 is charging and current flows through diode D1, switch S1, inductor L1, capacitor C1, load of R1 and capacitor C2. During the operation, the voltage across capacitor $\mathrm{C} 1$ is lower than the peak line voltage that regulated by PWM of switch S1 [14]. When switch S2 is turns off, inductor L1 discharged by freewheeling diode D3 to the load R1.

During negative half cycles on line voltage, switch S2 is turns on and the current flows through capacitor C2, charge the energy to inductor L2 and to the unidirectional diode of D2 in series with switch S2. The voltage across capacitor C2 during the operation is regulated by PWM of switch S2. As the switch S2 is turns off, inductor L2 is discharged by freewheeling diode of D4 to the load R1. During switch conduction, the current flows from the input line voltage of $\mathrm{V}_{\mathrm{AC}}$ is always through one diode either D1 or D2. Efficiency can be improved by terminating the input bridge diodes as the input current was carried by only two diodes.

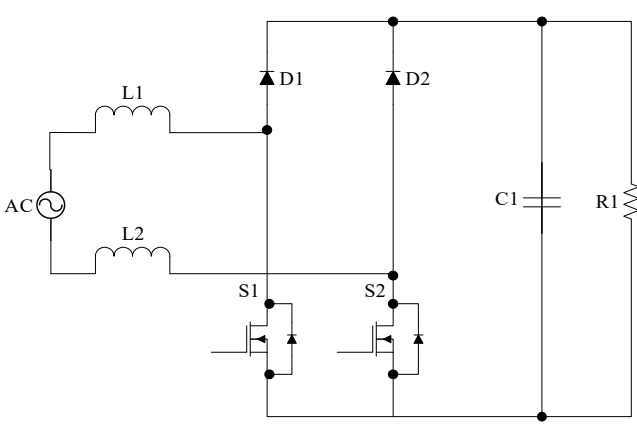

Figure 2. Bridgeless boost rectifier

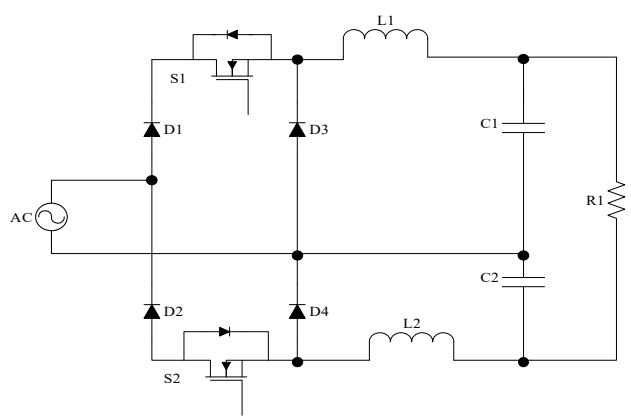

Figure 3. Bridgeless buck rectifier

\section{RESEARCH METHODOLOGY}

\subsection{Open loop (OL) control}

The first method in simulating the circuit is by using the open loop control. The open loop control is the simplest way to simulate the circuit in controlling the input voltage. The controller shown in Figure 4 represents the controller by using comparator in compare both duty cycle from dc voltage source and triangular-wave voltage source. The duty cycle is set based on the range of the calculation of duty cycle formula. It can be varied because the output voltage in open loop cannot be synchronized according to the duty cycle. Besides, the controller also consist of phase detector and a combination of logic gates. The comparator can only give positive half cycle output where the signal is positive output and represent the "high" signal. During the positive half cycle, the phase detector is in "high" as well. Hence, the signal from the comparator and phase detector will give the "high" to the positive inverter where is enable $\mathrm{AND}_{2}$. On the 
other hand, during the negative half cycle, the output from the phase detector is "zero". This will enable $\mathrm{AND}_{1}$ and disable $\mathrm{AND}_{2}$ which gives the "high" signal to the negative inverter.

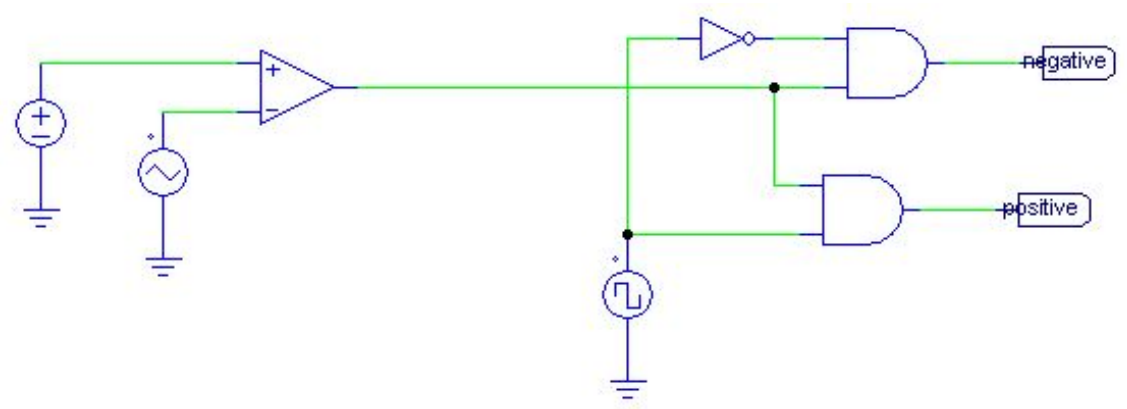

Figure 4. Open loop control

\subsection{Closed loop (CL) control}

Other than open loop control for UPS application, closed loop control has been represented to simulate the system for better power factor and efficiency as shown in Figure 5. It is another method that can be compared the performance in using the bridgeless boost and bridgeless buck as the converter in the UPS. Closed loop controller has two feedback loops which consist of voltage feedback loop and current feedback loop. The voltage feedback loop is to control the output voltage average value whereas the current feedback loop is to shape the sinusoidal current waveform at the input. In the closed loop control, the power factor preregulator has been used as the PF correction (PFC) to improve the power factor in the system.

To achieve the near unity PF, the input voltage and input current signals were represented and become the current and voltage references to the PF preregulator. By using this closed loop control, the duty can be set based on the expected output voltage as the controller will maintain the exact output voltage. The voltage sensor gain is set by 1:0.01. Hence, the expected duty cycle can be set by more than 0.48 in order to obtain 48 VDC of output voltage. The closed loop controller also used phase detector and combination logic gates as the open loop control for the UPS application. The phase detector is used to detect the phase from the input supply voltage yet to ensure that the gate signal is in phase and synchronized with the input supply. It is from the comparator where the sinusoidal input waveform is from main input voltage and it is connected to the noninverting terminal whereas the inverting terminal connected to the ground.

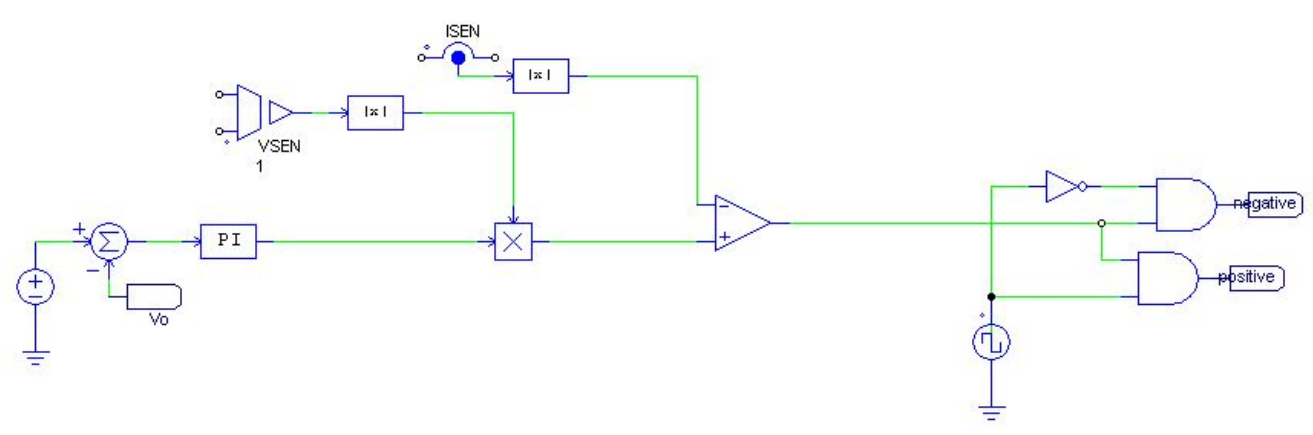

Figure 5. Closed loop control

\section{PROPOSED CONVERTER}

The proposed circuit is based on the topology from bridgeless boost circuit and has been modified and implemented to the basic UPS circuit system regardless the bridge rectifier as shown in Figure 6 . The supply voltage must be low as it will step up the supply voltage where the line voltage was set in around 12 $\mathrm{V}_{\mathrm{AC}}$. The desired output voltage for this circuit also is depends on the voltage of the battery and the boost

Int J Pow Elec \& Dri Syst, Vol. 11, No. 2, June 2020 : 801 - 809 
voltage must able to supply 1.2 times of the battery voltage to charge the battery. All the parameters were designed according to the expected results and can be varied as long as the output power and charging voltage can be maintained. The circuit is regulated by PWM and duty ratio for the circuit is followed by:

$$
D=1-\frac{V_{\text {in }}}{V_{\text {out }}}
$$

The duty cycle above is based on the Vin of $12 \mathrm{~V}_{\mathrm{AC}}$ and the output of $48 \mathrm{~V}_{\mathrm{DC}}$ and to get the optimum result, the duty cycle, $\mathrm{D}=0.68$.

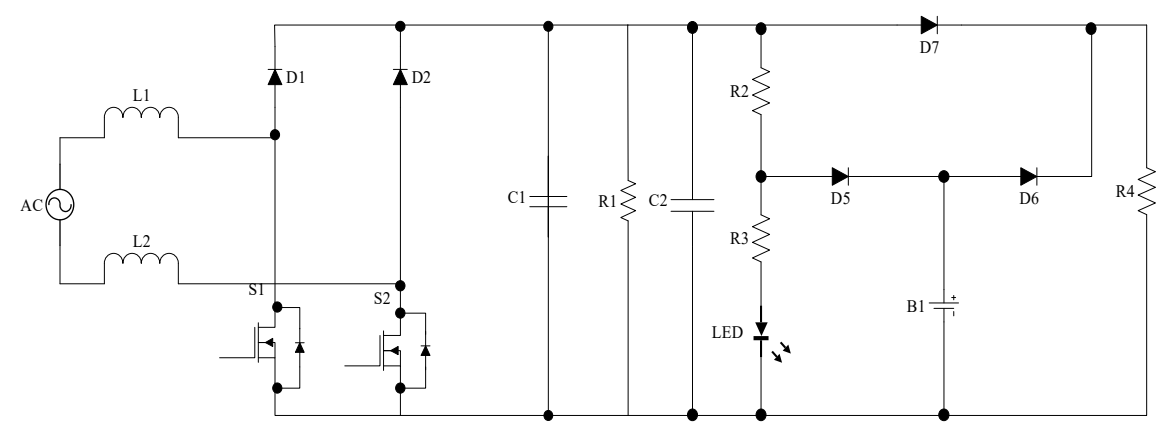

Figure 6. Bridgeless boost for UPS application circuit

\subsection{Bridgeless Buck for UPS Application}

The proposed bridgeless buck circuit shown in Figure 7 is based on the topology from bridgeless buck circuit and has been implemented to the UPS simple circuit regardless the bridge rectifier. The supply voltage must be high as the buck is step down the voltage and is around $90-230 \mathrm{~V}_{\mathrm{AC}}$. The desired output voltage is depending on the capacity of the battery and the buck voltage must able to cater the charging voltage of 1.2 times the output voltage of $48 \mathrm{~V}_{\mathrm{DC}}$. The duty cycle for buck can be calculated by using equation (2):

$$
D=\frac{V_{\text {out }}}{V_{\text {in }}}
$$

The above duty cycle can be obtained from the input of $90 \mathrm{~V}_{\mathrm{AC}}$ and output of $48 \mathrm{~V}_{\mathrm{DC}}$. For the optimum result, the duty cycle is set at $\mathrm{D}=0.25$. As both topology of boost and buck will be compared in terms of their performance, some values are equal for both circuits. The performance analysis of the bridgeless boost of UPS system is based on the efficiency and the time respond of the system during switching operation. The switch MOSFET between AC and DC part of the circuit resemble the switching operation and time when the circuit is take over by the DC to supply the load.

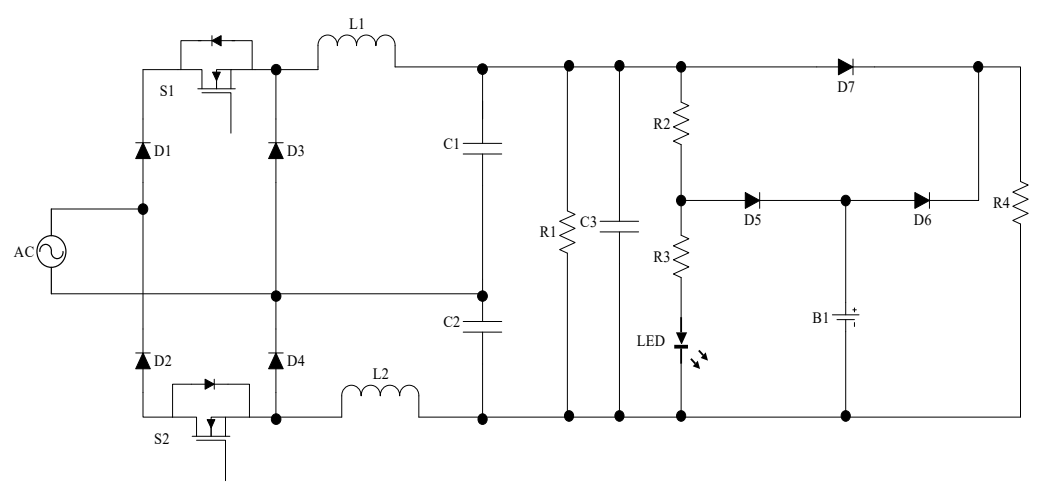

Figure 7. Bridgeless buck for UPS application circuit 


\section{RESULT ANS DISCUSSION}

The proposed boost and buck converters are simulated using PSIM with different parameters for every converter. However, the values of output power, Pout and output voltage, Vout have been set to make comparison for their performance. Figure 8 to Figure 12 show the waveform of the output voltage, Vout and output current, Iout from every topology. It can be said that the Vout is at $48 \mathrm{~V}_{\mathrm{DC}}$ by maintaining the Pout to be in range.

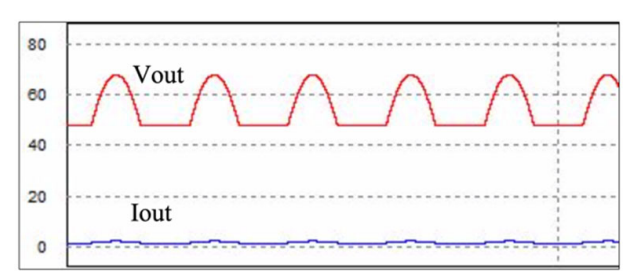

Figure 8. Vout and Iout of diode bridge rectifier

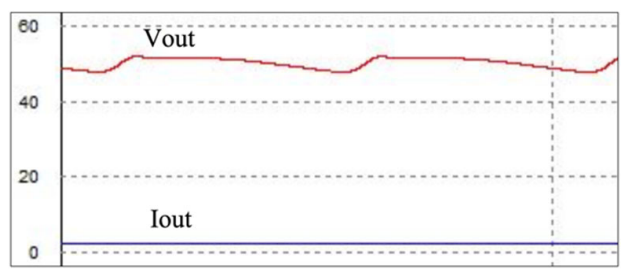

Figure 10. Vout and Iout of BL buck OL control

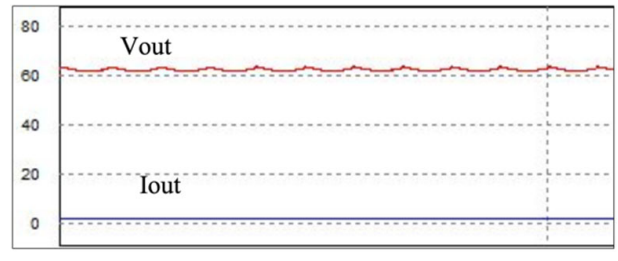

Figure 9. Vout and Iout of BL boost OL control

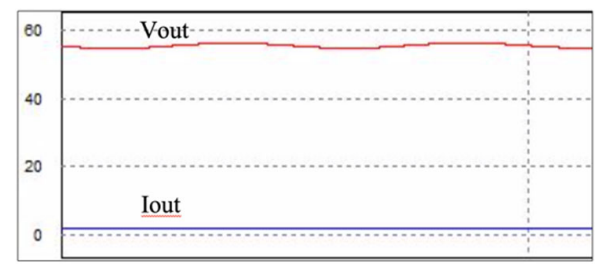

Figure 11. Vout and Iout of BL boost CL control

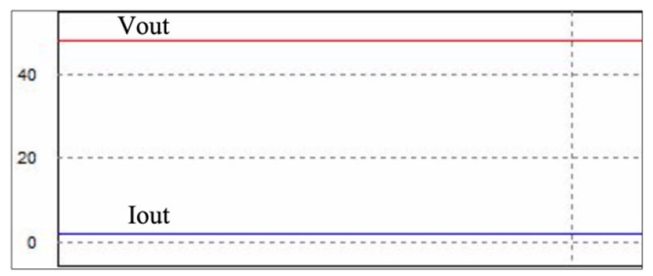

Figure 12. Vout and Iout of BL buck CL control

From Table 1, the output value is analyzed from the waveform obtained. The Vout is the expected output voltage to be more than $48 \mathrm{~V}$. It can be increase more in the future as long as in line with the expected result. The average Vout represent the normal condition with charging mode of the UPS. However, since it is the application for UPS system, the best Vout must able to reach 1.2 times voltage of the battery. In this system proposed, during normal condition, the supply voltage can supply directly to load while charging the battery of $48 \mathrm{~V}$. The output power, Pout is to be maintained between $100 \mathrm{~W}$ and $110 \mathrm{~W}$ to make a further performance comparison for all converters. Hence, the Pout is expected to be in range. When the expected output has been determined, the performance for every topology is analyzed and studied. Figure 13 to Figure 17 show the waveforms of input voltage, Vin and input current, Iin in different topology. From the waveforms, the performance can be analysed by observing their current waveforms. All the topologies are operated based on the theoretical analysis and works accordingly with the simulation results. The aim is to see the waveform of the Iin to be in phase with the Vin waveform. However, the diode bridge in Figure 13 is giving the most distorted waveform followed by buck converter as in Figure 15. BL buck converter is giving some nearest Iin sinusoidal waveform especially when using closed loop converter as in Figure 17, but the distorted line is still appear due to harmonics. The waveforms can be compared with the usage of boost converter where the Iin waveform is almost in line with Vin waveform. BL boost converter in Figure 14 can be considered to be able to regulate the Iin and make it fundamentally in phase with Vin. The waveforms of

Int J Pow Elec \& Dri Syst, Vol. 11, No. 2, June 2020 : $801-809$ 
Iin can be seen both in proposed controller for BL boost and the best is in BL boost of closed loop controller as in Figure 16.

Table 1. Analysis of output in different topology

\begin{tabular}{lccc}
\multicolumn{4}{c}{ Table 1. Analysis of output in different topology } \\
\hline Topology & Vout (V) & Iout (A) & Pout (W) \\
\hline Diode Bridge & 86.70 & 1.08 & 105.50 \\
BL Boost & 62.43 & 1.78 & 110.02 \\
BL Buck & 50.38 & 2.19 & 110.24 \\
BL Boost PFC & 56.84 & 1.89 & 107.78 \\
BL Buck PFC & 48.02 & 2.18 & 104.82 \\
\hline
\end{tabular}

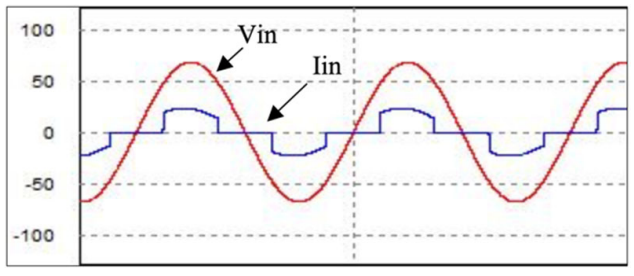

Figure 13. Vin and Iin of diode bridge rectifier

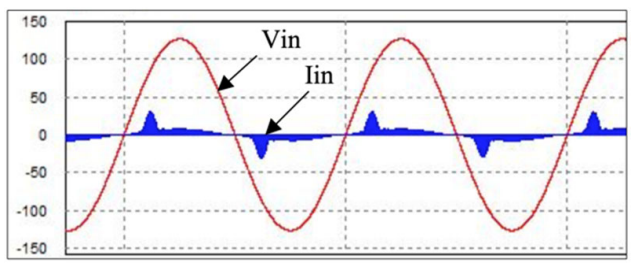

Figure 15. Vin and Iin of BL buck OL control

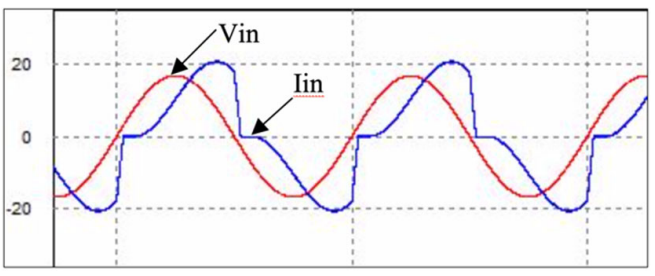

Figure 14. Vin and Iin of BL boost OL control

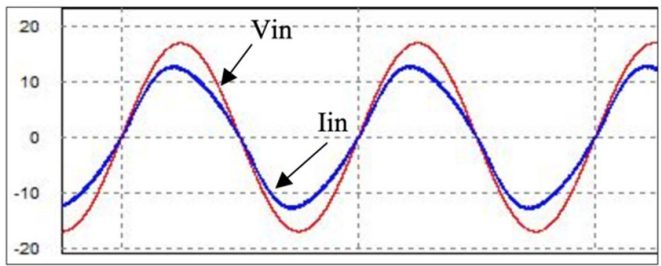

Figure 16. Vin and Iin of BL boost CL control

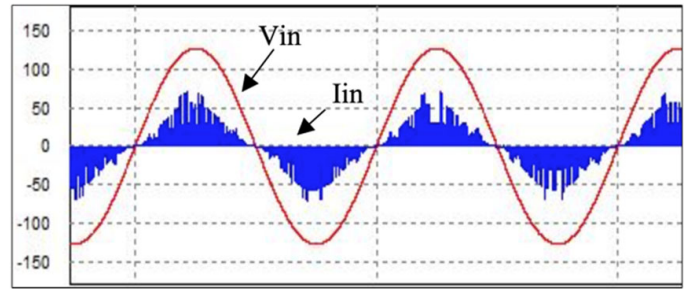

Figure 17. Vin and Iin of BL buck CL control

Table 2 shows the analysis on the input side based on the simulated waveforms. It can clearly see that BL Boost will have high Iin if compared to other topology. The input in the diode bridge topology has a very high value of power supply.

Table 2. Analysis of input in different topology

\begin{tabular}{lccc}
\hline Topology & Vin $(\mathrm{V})$ & Iin $(\mathrm{A})$ & Pin $(\mathrm{W})$ \\
\hline Diode Bridge & 89.80 & 3.36 & 205.92 \\
BL Boost & 12.00 & 13.56 & 112.28 \\
BL Buck & 89.89 & 4.36 & 129.33 \\
BL Boost PFC & 12.00 & 9.28 & 110.91 \\
BL Buck PFC & 89.89 & 1.88 & 114.82 \\
\hline
\end{tabular}

In comparing all the topologies proposed, the finalize performance of their efficiency and PF are analysed as in Table 3. By using the diode bridge rectifier, the efficiency is inefficient since the efficiency is

\footnotetext{
Comparative performance analysis of bridgeless boost and bridgeless buck ... (Khairul Safuan Muhammad)
} 
$51 \%$. The PF result from the simulation is in the best range but cannot be fairly compared with other topologies. Because of the performance of the diode bridge rectifier in UPS is giving unsatisfactory performance theoretically and in simulation, the BL converters of boost and buck have been proposed and compared. From the analysis, the BL boost is giving the best result than BL buck. It can be seen in all terms where the highest efficiency between those two converters is BL boost. Although BL boost of open loop controller gives the highest efficiency of $97 \%$, the PF is still not in a good range of accepted PF which is 0.69. BL buck with open loop controller is giving a very low PF of 0.33 and it is considered as a very bad system if apply to the UPS system. Hence, another topology is presented by using the same topology of BL boost and BL buck but in difference controller which is closed loop controller.

Table 3. Comparison of efficiency and PF in different topology

\begin{tabular}{lcc}
\hline Topology & Efficiency (\%) at Pout=100W-110W & PF \\
\hline Diode Bridge & 51 & 0.97 \\
BL Boost & 97 & 0.69 \\
BL Buck & 85 & 0.33 \\
BL Boost PFC & 97 & 0.98 \\
BL Buck PFC & 91 & 0.68 \\
\hline
\end{tabular}

The closed loop controller is another level of method to improve the PF and act as a PFC. The ability of this method is proven by simulation results. Based on the Table 3, the efficiency of the BL boost open loop control and BL boost closed loop control not giving any difference but, the PF is improved by 0.29 . In comparing the BL buck open loop and BL buck closed loop, it has increase by $6 \%$ of efficiency and increase the PF by 0.35 as well.

Thus, closed loop controller gives better performance than open loop controller in UPS system. Between those two of converters of BL boost and BL buck, it is precise the ability of BL boost to give better performance for UPS application.

\section{CONCLUSION}

In a conclusion, the best converter for UPS application is by using bridgeless boost converter with a combination of closed loop controller. All the simulation and analysed data were sided to the BL boost with closed loop controller since the waveform is the most fundamentally in phase with its input voltage and the simulated PF is the highest among other converter arrangement. The efficiency is also high i.e. $97 \%$ efficient and it is surely is suitable for UPS application. With all the proven data and analysis, it is no doubt to state that bridgeless boost converter with closed loop controller gives the best performance for UPS application and reduce the conduction losses in the system by improving the efficiency and PF.

\section{REFERENCES}

[1] N. Kannan and D. Raja, "Interleaved bridgeless PFC rectifier for UPS application using current controllers," in Proc. IEEE Int. Conf. on Electrical, Comp. and Communication Technologies, 2015.

[2] E. K. Sato, M. Kinoshita and K. Sanada, "Double DC-DC converter for uninterruptible power supply applications." in Proc. Inter Power Conference ICCE ASIA, 2010.

[3] R. Caceres, et al.," A high performance uninterruptible power supply system with power factor correction." in Proc. Power Electron. Spec. Conf. 1997.

[4] U. G. Scholar, "Bridgeless Based Online Transformers UPS Power Supply System For Energy Storage," Int. J. Adv. Res. Basic Eng. Sci. Technol., vol. 3, no. 24, 2017.

[5] F. Musavi, W. Eberle, and W. G. Dunford, "Efficiency evaluation of single-phase solutions for AC-DC PFC boost converters for plug-in-hybrid electric vehicle battery chargers," 2010 IEEE Veh. Power Propuls. Conf. VPPC 2010, pp. 1-6, 2010.

[6] M. Alam, W. Eberle, D. S. Gautam, and C. Botting, "A Soft-Switching Bridgeless AC-DC Power Factor Correction Converter," IEEE Trans. Power Electron., vol. 32, no. 10, pp. 7716-7726, 2017.

[7] R. Sasikala and R. Seyezhai, "Review of AC-DC power electronic converter topologies for power factor correction," International Journal of Power Electronics and Drive System (IJPEDS), Vol. 10, No. 3, pp. 15101519, Sep 2019.

[8] Nabil Mohammed, et al., "Design, Control and Monitoring of an Offline Mobile Battery Energy Storage System for a Typical Malaysian Household Load Using PLC," International Journal of Power Electronics and Drive System (IJPEDS), Vol. 9, No. 1, pp. 180-188, 2018.

[9] H. Matsuo, L. Tu, F. Kurokawa, and H. Watanabe, "A novel soft-switching buck-boost type AC-DC converter with

Int J Pow Elec \& Dri Syst, Vol. 11, No. 2, June 2020 : $801-809$ 
high power efficiency, high power factor and low harmonic distortion," IEEE Power Electron. Spec. Conf., vol. 2, pp. 1030-1035, 1998.

[10] Santhi Mary Antony, Godwin Immanuel, "A Novel Single-Phase bridgeless AC/DC PFC converter for Low Total Harmonics Distortion and High-Power Factor" International Journal of Power Electronics and Drive Systems (IJPEDS), Vol. 9, No. 1, pp. 17-24, March 2018.

[11] Y. Jang, "Bridgeless High-Power-Factor Buck Converter," IEEE Trans. Power Electron., vol. 26, no. 2, pp. 602 $611,2011$.

[12] D. Jaiswal et al., “Analysis of Bridgeless PFC Boost Converter,” Int. J. Eng. Res. Technol., vol. 1, no. 5, pp. 1-7, 2012.

[13] K. S. Muhammad and D. D. Lu, "Single-phase Single-stage ZCS Boost PFC Rectifier with Reduced Switch Count," Australas. Univ. Power Eng. Conf., vol. 3, no. October, pp. 1-6, 2014.

[14] K. Muhammad and D.-C. Lu, "Two-switch ZCS totem-pole bridgeless PFC boost rectifier," in Proc. IEEE PECon, Dec. 2012, pp. 1-6.

[15] M. Mahdavi and H. Farzanehfard, "Zero-voltage transition bridgeless single-ended primary inductance converter power factor correction rectifier," IET Power Electron., vol. 7, no. 4, pp. 895-902, Apr. 2014.

[16] J .-W. Shin, S.-J. Choi, and B.-H. Cho, "High-efficiency bridgeless flyback rectifier with bidirectional switch and dual output windings," IEEE Trans. Power Electron., vol. 29, no. 9, pp. 4752-4762, Sep. 2014

[17] Y. Jang and M. M. Jovanovi, "Bridgeless Buck PFC Rectifier," Power Electron. Lab. Delta Prod. Corp., pp. 2329, 2010.

[18] Y. Jang and M. M. Jovanović, "Bridgeless high-power-factor buck converter," IEEE Trans. Power Electron., vol. 26, no. 2, pp. 602-611, 2011.

[19] B. Zhao, A. Abramovitz, and K. Smedley, "Family of Bridgeless Buck-Boost PFC Rectifiers," IEEE Trans. Power Electron., vol. 30, no. 12, pp. 6524-6527, 2015.

[20] Nor Akmal Rai, et al., "Bridgeless PFC single ended primary inductance converter in continuous current mode," International Journal of Power Electronics and Drive System (IJPEDS), Vol. 10, No. 3, pp. 1427-1436, 2019.

[21] Meena Devi R and L. Premalatha, "Soft Computing Technique of Bridgeless SEPIC Converter for PMBLDC Motor Drive," International Journal of Power Electronics and Drive System (IJPEDS), Vol. 9, No. 4, pp. $1503-$ $1509,2018$.

[22] A. V. Da costa, C. H. G. Treviso, and L. De Freitas, "A new ZCS-ZVSPWM boost converter with unity power factor operation," in Proc. IEEE APEC, 1994, pp. 404-410.

[23] C. da Cunha Duarte and I. Barbi, "A new ZVS-PWM active-clamping high power factor rectifier: Analysis, design, experimentation," in Proc. IEEE APEC, 1998, pp. 230-236.

[24] C. Canesin and I. Barbi, "A novel single-phase ZCS-PWM high-powerfactor boost rectifier," IEEE Trans. Power Electron., vol. 14, no. 4, pp. 629-635, 1999

[25] L. Huber, Y. Jang, and M. Jovanovic, "Performance evaluation of bridgeless PFC boost rectifiers," IEEE Trans. Power Electron., vol. 23, no. 3, pp. 1381-1390, 2008.

[26] H.-Y. Tsai, T.-H. Hsia, and D. Chen, "A family of zero-voltage-transition bridgeless power-factor-correction circuits with a zero-current-switching auxiliary switch," IEEE Trans. Ind. Electron., vol. 58, no. 5, pp. 1848-1855, 2011. 